\title{
The Primates 2018 Most-Cited Paper Award is conferred upon James R. Anderson and Gordon G. Gallup Jr.
}

\section{Tetsuro Matsuzawa ${ }^{1,2}$}

Published online: 15 October 2018

๑) Japan Monkey Centre and Springer Japan KK, part of Springer Nature 2018

The paper by James R. Anderson and Gordon G. Gallup Jr., entitled "Mirror self-recognition: a review and critique of attempts to promote and engineer self-recognition in primates." (Anderson and Gallup 2015) was cited most frequently in 2017 among those published in Primates during the period from 2015 to 2016.

The authors thus contributed greatly to enhancing the reputation of our journal. For this achievement, the authors receive declarations attesting to their contributions from the Japan Monkey Centre, the Primate Society of Japan, and Springer.

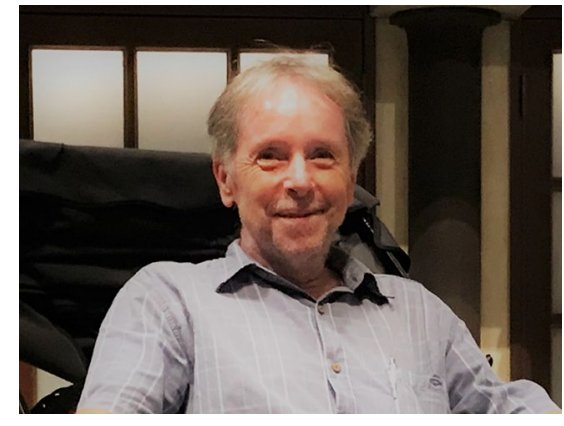

James R. Anderson

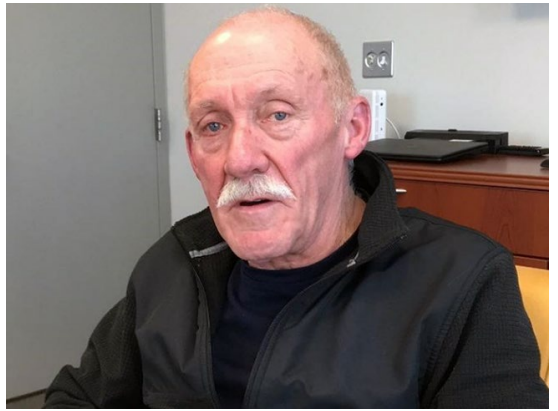

Gordon G. Gallup Jr.

10 September 2018

Tetsuro Matsuzawa:

Tetsuro Matsuzawa:

General Director, Japan Monkey Centre

Masayuki Nakamichi: Editor-in-Chief, Primates

Alexandrine Cheronet:

President, Primate Society of Japan

Executive Editor, Springer, a part of Springer Nature

\section{Reference}

Anderson JR, Gallup GG Jr (2015) Mirror self-recognition: a review and critique of attempts to promote and engineer self-recognition in primates. Primates 56:317-326. https://doi.org/10.1007/s1032 9-015-0488-9

Tetsuro Matsuzawa

matsuzawa.tetsuro.8w@kyoto-u.ac.jp

1 Kyoto University, Kyoto, Japan

2 The Japan Monkey Centre, Inuyama, Japan 